\title{
AN INITIAL STUDY OF A LIGHTWEIGHT DIE CASTING DIE USING A MODULAR DESIGN APPROACH
}

\author{
Sebastian Müller (1) and Klaus Dilger (1) \\ Institute of Joining and Welding, Technische Universität Braunschweig, Braunschweig, Germany
}

Anke Müller $\mathbb{B}$, Felix Rothe $\mathbb{B}$, and Klaus Dröder $(\mathbb{B}$

Institute of Machine Tools and Production Technology, Technische Universität Braunschweig, Braunschweig, Germany

Copyright $@ 2018$ The Author(s)

https://doi.org/10.1007/s40962-018-0218-3

\begin{abstract}
High-pressure die casting dies are produced in most cases by conventional subtractive manufacturing processes. In this case, a massive design of the die usually ensures high stability during the casting process. However, at the same time, it leads to low flexibility in casting production and high material costs. The basic approach in the present work is to reduce the conventional subtractive production process of a die casting die in favor of a flexible, modular design, where only a few contour elements of the die have

out showed that the modular lightweight die casting die consumes considerably less energy for preheating and during operation. Due to the reduced stiffness and material, however, calculated deformations and stresses in the die are considerably higher during the casting process. Although the initial calculation results look very promising, further knowledge must be gained in order to ensure the future success of modular lightweight die casting dies.
\end{abstract} to be replaced for achieving different castings. In order to pave the way for this design principle, basic thermal and structural properties of a lightweight design die casting die were analyzed. The finite element calculations carried
Keywords: die casting, process modeling, die deflections, lightweight design, modular concept, energy reduction

\section{Introduction}

The high-pressure die casting (HPDC) process is a highly automated industrial casting process and is used in particular for the production of geometrically complex components. As a tool-linked production process, it is classically predestined for high lot sizes. Almost $70 \%$ of German production is, therefore, currently accounted for by the automotive industry. ${ }^{1}$ In the field of die casting, a die casting die is usually redesigned and manufactured for each individual component. There is currently no official standard or even cross-company standardization of the individual components within the die. Rather, the advances in the design process in companies have evolved in an evolutionary way. These improvements are primarily the result of the designers' experience, which results from the proven performance of die casting dies in operation as well as from the application of numerical calculation and optimization methods. Together with the cavity die and other components (ejector pins, sliders, cooling system, ejector plate), the mold base represents the functional unit die casting die. The primary task of the mold base is to fix the cavity die, absorb forces that occur during the production process and ensure a reliable integration of the components mentioned above. The mold base is currently manufactured subtractively by machining large steel blocks. In order to achieve sufficient stiffness and strength, the mold base is generally well dimensioned. However, the technological design approach currently used is associated with numerous disadvantages, which must be avoided:

- High investment costs for die casting dies limit this manufacturing process to products that are required in high quantities,

- The operation of large die casting dies results in a high-energy consumption during operation and, as a further consequence, in a slow die temperature control,

- High total weights of die casting dies require sufficient overall stiffness of the die casting 
machine as well as an appropriate dimensioning of drive units, otherwise the die casting process lacks stability and dynamics,

- Operational loadings on the die casting die during casting production processes are not sufficiently known, which often results in oversizing of the respective components,

- An energy-intensive production of quenched and tempered tool steels leads to a high $\mathrm{CO}_{2}$ footprint for the die casting die and, ultimately, to increased emissions in the final product; apart from the mold base, the die casting die is usually not reused but scrapped,

- Shape and dimension of the forming frame often require time-consuming and material-intensive machining processes of the applied tool steel (e.g., the alloy $40 \mathrm{CrMnMoS} 8-6$ ). ${ }^{2}$

The aim should, therefore, be to simplify the time-consuming and cost-intensive design and manufacturing process of die casting dies and to enable rapid implementation of product variants. This article, therefore, presents a concept for a modular lightweight die casting die in order to make the time-consuming and cost-intensive design and manufacture of the dies more efficient.

\section{Literature Review}

The high-pressure die casting process can be regarded as a dominant process for the production of lightweight components. According to Brecher, ${ }^{3}$ the growing demand for individualized products is a major challenge for this industry. The complexity of this task derives from the fact that the die casting process is a die-based production process. Hence, the die casting process is, therefore, strongly influenced by tooling costs and design. Queudeville stated that costs for the dies need to be decreased significantly in order to qualify the process for smaller lot sizes and to bring it closer to a one-piece flow. Moreover, Queudeville also identified the cost drivers with a high impact on the overall costs: costs for the raw material, the manufacturing itself and the development of the die design. ${ }^{4}$ A strategy to overcome this problem is seen in the modularization of die casting dies. Several attempts have already been made in the industry to establish a modular design for die casting dies. For the production of cylinder crankcases with two, three or four cylinders, a modular die casting die with interchangeable cavity dies was developed. ${ }^{5}$ In this field, Queudeville et al. have also analyzed the modularization and standardization of high-pressure die casting dies, ${ }^{6}$ aiming at breaking the one-to-one relationship between the cast part and the corresponding casting die. It was found that modularization and standardization of dies can be a promising method for a company. However, there are several reasons why it makes no sense to implement this method to every component of a die. ${ }^{7}$ On the one hand,
Mikkola and Gassmann emphasized that it would be easy for competitors to copy a die casting die, if it is only composed of standard elements. ${ }^{8}$ On the other hand, modularization of die casting dies increases the complexity of the design process and makes it more expensive. Therefore, this approach is only reasonable if the influence of the standardized component on total costs is significant or if standardization is easy to achieve. In this context, components of great importance are the mold base and cavity die. Nevertheless, technical reasons remain that prevent a die design entirely based on standardized components. The gating system and the temperature control system of the die are named as important and at the same time individual components. ${ }^{3}$ The individual requirements here often do not permit a technically feasible or economic modularization.

No further information was found on research results regarding lightweight design concepts for die casting tools. However, a design concept for the energy-efficient forming of polystyrene (PS) and polypropylene (PP) particle foams was published, also providing results on the lightweight design of forming tools. ${ }^{9}$ The weight reduction in the forming tool is achieved, among other concepts, by means of hollow sphere structures. Based on the experiments carried out, the suitability of hollow sphere structures as a mold material for particle foam parts could be proven. Furthermore, simulations and laboratory measurements have shown that an increase in energy efficiency-in the case of the hollow sphere structures, approx. 65\%-could be reached.

Barone and Caulk used the software DieCAS, a boundary element-based computer code for the thermal analysis of the die casting process, for predicting thermally induced deflection in transmission casing dies. ${ }^{10}$ For this purpose, temperature data from the thermal simulation were transferred to a thermoelastic model of the die casting die. Furthermore, Hedge et al. ${ }^{11,12}$ developed simulation methods based on ABAQUS to predict the behavior of a die under thermal loads due to the solidification process as well as mechanical loads caused by the injection pressure and the locking force of the die casting machine. It was found that thermally induced deflections account for most of the deviations from die dimensions at room temperature, the deflection of the cavities caused by mechanical loads is typically smaller by about an order of magnitude. AhuettGarza and Miller analyzed the cavity filling process and defined conditions for a significant heat release during the casting process. These conditions are given in terms of the thickness of the casting and the cavity fill times. ${ }^{13}$ It was shown that the deflection depends strongly on the basic temperature of the die casting die, which is relatively insensitive to the redistribution of heat within the casting. On the other hand, however, the calculation of thermal fields in the presence of significant heat release is of high importance because the induced variations in die 
deflections are of the same order of magnitude as achievable tolerances in die castings. The authors state that an accurate prediction of die deflections can help control dimensional variability of the cavity and, in turn, enhance achievable tolerances in die casting.

In Reference 14 , the die stress was successfully measured with strain gauges at the rear surface of the die and compared to a MAGMASOFT casting simulation model in order to provide greater confidence in the stress results of the simulation model. This comparison showed that there is a good correlation (a difference of approximately 10\%) between the results from the casting simulation software and instrumentation trial. External loadings such as die closing force and metal injection pressure were not simulated with the casting software. However, results from FE analyses showed that the die closing force and metal injection pressure have very little effect on the resulting die surface stress in this case. In addition, the work contains valuable information on the experimental determination of strains in die casting dies. The methods developed here can also be used for the measurement of die and machine platen deflections.

Another study presented in Reference 15 aims at a die design based on a casting simulation and a mold base structural simulation in order to manufacture automotive clutch housing aluminum parts in a HPDC process. A structural simulation of the mold base was carried out here in order to predict possible damage at critical areas of the mold frame. A standard range of deformation $(0.20-0.25 \mathrm{~mm})$ has been defined for the mold base which must not be exceeded. The mold base thickness was adjusted until the calculated deformations were within the specified range. The authors Yamagata et al. also emphasize the importance of die design and the high influence of the die deflection on the dimensional accuracy of HPDC parts. ${ }^{16}$ A computational method was developed to estimate the die deflection in an HPDC process. The considerations take into account both the deflection of the cavity die caused by locking forces and by thermal distortion. An actual distortion measurement of the cavity die demonstrated that the calculation including the machine platen could precisely predict the deformation of the cavity die. From these steps, it was clarified that the computer simulation on the HPDC system including the structural machine can precisely evaluate the deflection of the die insert. This publication is particularly valuable as it provides concrete information on the boundary conditions used.

\section{Modular Concept of a Lightweight Design Die Casting Die}

The following chapter presents the design principle of the lightweight design die. As a reference HPDC component, the existing 4-mm plate was selected. In addition to the geometric advantages of the plate with regard to a deformation analysis (see Section "Simulation Results"), the performance of the design can also be compared with a real die casting die. Therefore, the cavity geometry was not changed either. Figure 1 serves to illustrate the basic design principle of the lightweight design die. As may be seen in Figure 1, the general concept of a die casting die for the HPDC process remains unchanged. The die casting die consists of a cavity die and a mold base that surrounds the cavity die. This principle applies to the fixed and ejector die half. However, major differences can be found in the design of the mold base. In contrast to the conventional mold base, which usually is made of a solid block of steel, a highly segmented design was used here. The mold base consists of a space frame, a rigid, lightweight, truss-like structure constructed from interlocking struts in a geometric pattern. Due to the inherent rigidity of a triangle, bending moments are transmitted as tension and compression loads along the length of each strut. In this design study, the struts have an outer diameter of $12.5 \mathrm{~mm}$ with a wall thickness of $2.5 \mathrm{~mm}$ and are connected to the surrounding frame by knots. The optimum design of the space frame is derived from the requirements and loads of the die casting process. Within the scope of this design study, it was assumed that the main load direction is according to the arrows displayed in Figure 1b, leading to a torsion of the whole space frame. Each half of the space frame consists of five surfaces (left/right, top/bottom, front). Based on the symmetry boundary condition, only three different trusses were thus considered. A method detailed in References 17, 18 was enabled to calculate the optimal design of the individual trusses. For this purpose, a MATLAB script developed by the authors was used. One of the surrounding frames also bears the cavity die. The cavity die is exposed to high loads; therefore, its load-bearing structure requires superior strength and stiffness. At the same time, the load-bearing structure also needs to provide access for ejector pins (at the moving die half) and for cooling channels. Accordingly, an optimal design is, next to the design of the mold base, a key factor for the success of the whole design principle. Within the scope of this design study, this is established by an individually dimensioned lightweight load-bearing metal structural element (Figure 1a, \#8) as well as by load-bearing columns (Figure 1a, \#6). The metal elements features regularly arranged recesses, which provide necessary access for ejector pins and cooling channels (not visible in Figure 1). The baseplate (see Figure 1a, b, \#10) allows to integrate the ejector plate as well as the ejector retainer plate, ensuring the functionality of the die casting die. The cavity of the lightweight design die corresponds exactly to the cavity of the conventional die. However, due to the increased space required for the design principle with the space frame, the outer dimensions of the lightweight design die are larger than the outer dimensions of the conventional die (735 mm resp. $600 \mathrm{~mm}$; see Figure 2). In addition, it is important to note that the lightweight die, unlike the conventional die, has no guide pins-round pins at the four ends of the die to assure the alignment of the two die halves. This is feasible for this special HPDC component 


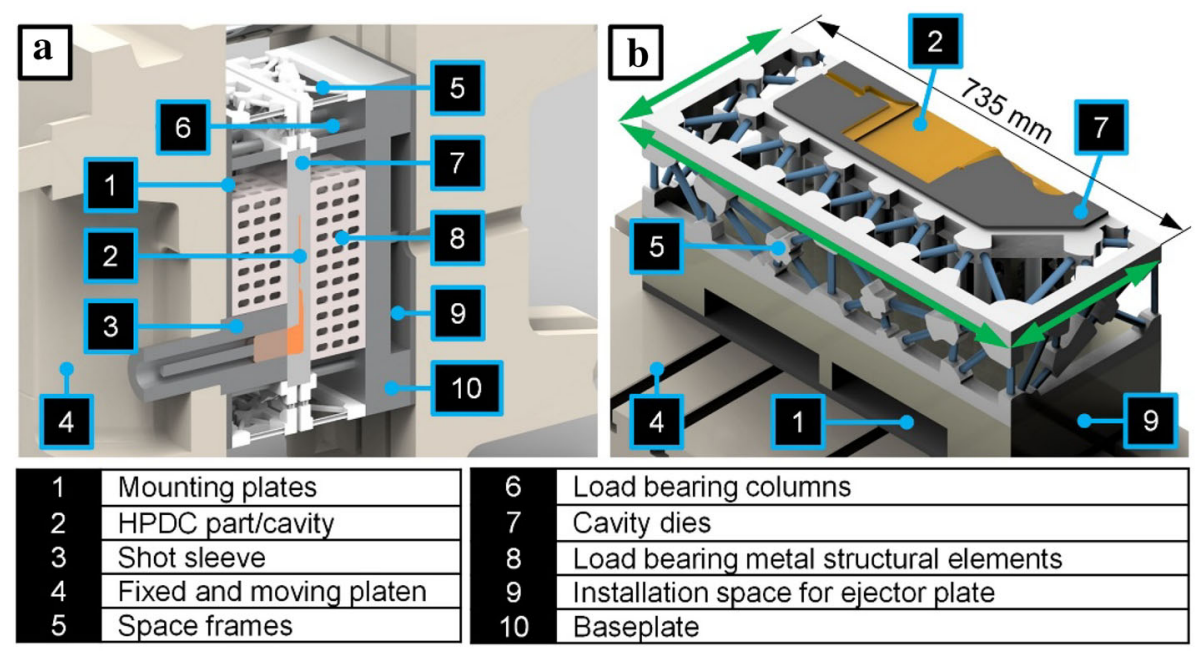

Figure 1. Cross-sectional (a) and isometric (b) view of the lightweight design die.
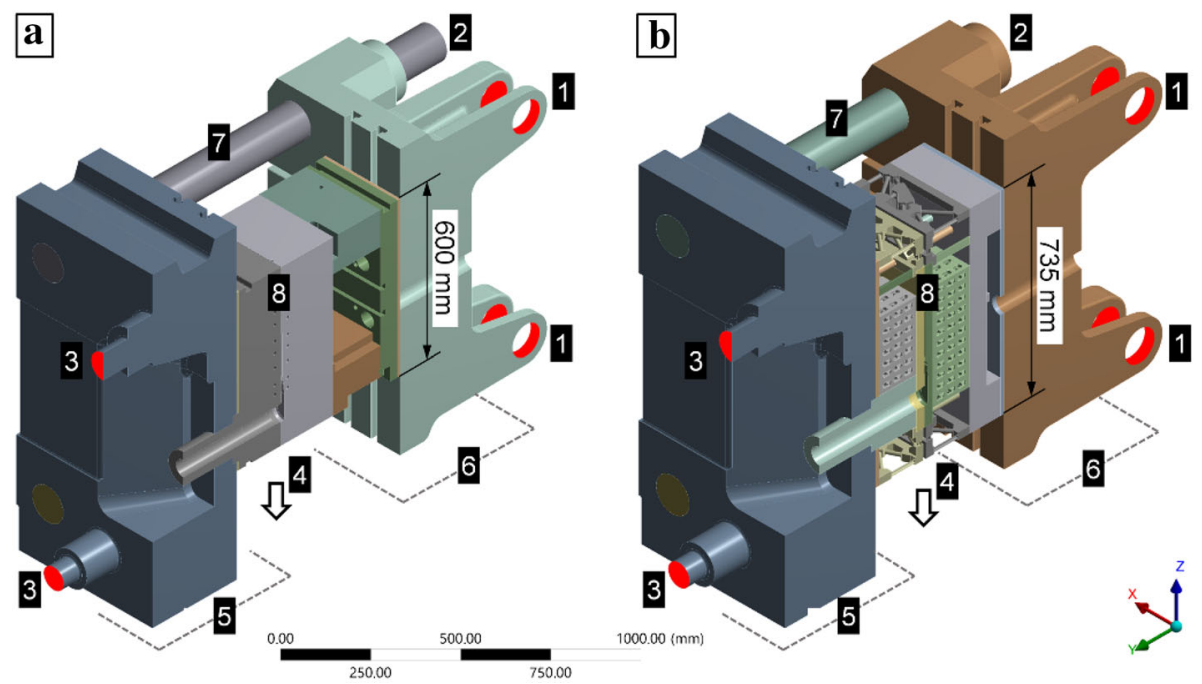

Figure 2. Illustration of boundary conditions for the finite element model; (a) conventional die casting die, (b) lightweight design die; see Table 1 for notes on 1-8.

geometry, as the cavity is only located in the moving die half of the die casting die. The total weight of the lightweight design die is calculated to $690 \mathrm{~kg}$ (the non-optimized baseplate alone accounts for $280 \mathrm{~kg}$ ). Considering the total weight of the conventional die casting die $(1570 \mathrm{~kg}$, see Figure $2 b$ ), a weight reduction factor of about 2.3 is calculated. For a concrete manufacturing process, of course, this study would have to be further detailed. However, care was taken to ensure that the design principle can also be realized in terms of the manufacturing technology.

\section{Simulation Model}

A simulation model was prepared in ANSYS in order to study the mechanical and thermal behavior of a lightweight (a) and conventional (b) die casting die during operation (see Figure 2). For this study, the CAD design of the lightweight die concept as well as the existing CAD data of a conventional die casting die were enabled. The CAD data for the fixed and moving platen of the die casting machine BUEHLER SC B53 were provided by the manufacturer. This die casting machine, a horizontal cold chamber machine with a locking forces of $5500 \mathrm{kN}$, as well as the conventional die casting die are in regular operation in the research foundry of the Institute of Joining and Welding. The finite element model consists of a coupled transient thermal and structural analysis. As the die casting process is characterized by a wide range of thermal and mechanical loads, corresponding boundary conditions must be set carefully. Detailed information on the boundary conditions can be taken from Table 1. Some of the mechanical boundary conditions applied in this model are partly based on procedures published in Reference 16. The casting 
Table 1. Boundary conditions mainly related to mechanical behavior of the die casting die

\begin{tabular}{|c|c|c|}
\hline No. & Parameter & Value \\
\hline & Total projected area of casting & $56,844 \mathrm{~mm}^{2}$ \\
\hline & $\begin{array}{l}\text { Locking force BUEHLER SC B53 } \\
\text { evolution }\end{array}$ & $530 t$ \\
\hline & Safety factor for locking force & 1.1 \\
\hline & Moving and fixed platen material & $\begin{array}{l}\text { Lamellar } \\
\text { graphite cast } \\
\text { iron }\end{array}$ \\
\hline & Die casting die material & AISI H11 \\
\hline 1 & $\begin{array}{l}\text { Locking force on moving platen } \\
\text { (symmetric model) }\end{array}$ & $Y=2360 \mathrm{kN}$ \\
\hline \multirow[t]{3}{*}{2} & $\begin{array}{l}\text { Counter force on each machine bar } \\
\text { (symmetric model) }\end{array}$ & $Y=-1180 \mathrm{kN}$ \\
\hline & $\begin{array}{l}\text { Applied metal injection pressure } \\
\text { ( } 72 \% \text { of maximum pressure) }\end{array}$ & 600 bar \\
\hline & Piston diameter & $60 \mathrm{~mm}$ \\
\hline 3 & $\begin{array}{l}\text { Piston counter force on fixed platen } \\
\text { (symmetric model) }\end{array}$ & $42.4 \mathrm{kN}$ \\
\hline 4 & Standard earth gravity & $9.81 \mathrm{~m} / \mathrm{s}^{2}$ \\
\hline 5 & Support of fixed platen (bottom area) & $X / Y I Z=0$ \\
\hline 6 & $\begin{array}{l}\text { Support of moving platen (bottom } \\
\text { area) }\end{array}$ & $Z=0$ \\
\hline 7 & $\begin{array}{l}\text { Support of machine bars in moving } \\
\text { platen }\end{array}$ & Frictionless \\
\hline 8 & Interface area between tool inserts & Frictionless \\
\hline
\end{tabular}

boundary conditions used in this model are derived from the real production process with the conventional die casting die. In particular, the metal injection pressure of 600 bar orients itself to the real requirements of the casting process. Other authors report on successful investigations with a metal injection pressure of 100-200 bar. ${ }^{19}$ However, these values are regarded as too low by the authors of this article.

Figure 2 illustrates the applied boundary conditions for both dies. The values for the applied locking force and for the metal injection pressure correspond to the values applied in regular casting operation. Other values were directly derived from these basic values. According to the regular casting process, the moving platen is allowed to move in y-direction along the machine bars (axial support) against the other die half attached to the fixed machine platen. However, in contrast to the real casting process, sliding is set to frictionless since no valid data are available here and it is assumed that the effect is negligible. Since the cavity geometry, the die casting die as well as the fixed and moving platen are symmetrical with respect to the $\mathrm{x}$-axis, symmetry boundary conditions were enabled for both models in order to save computing times. The meshing of the lightweight die turned out to be a challenging task, due
Table 2. Boundary conditions mainly related to the thermal behavior of the die casting die

\begin{tabular}{lc}
\hline Parameter & Value \\
\hline Heating period (only cooling channels active) & $14,400 \mathrm{~s}$ \\
HTC between tools & $10,000 \mathrm{~W} /$ \\
& $\left(\mathrm{m}^{2} \mathrm{~K}\right)$ \\
HTC between casting and tool surface & $20,000 \mathrm{~W} /$ \\
& $\left(\mathrm{m}^{2} \mathrm{~K}\right)$ \\
HTC in cooling channels & $1500 \mathrm{~W} /$ \\
& $\left(\mathrm{m}^{2} \mathrm{~K}\right)$ \\
Temperature of the cooling fluid & $250^{\circ} \mathrm{C}$ \\
HTC during spraying (cavity and surrounding & $15,000 \mathrm{~W} /$ \\
areas): & $\left(\mathrm{m}^{2} \mathrm{~K}\right)$ \\
HTC during spraying (areas outside spray & $3000 \mathrm{~W} /$ \\
cone): & $\left(\mathrm{m}^{2} \mathrm{~K}\right)$ \\
HTC during blowing & $1000 \mathrm{~W} /$ \\
& $\left(\mathrm{m}^{2} \mathrm{~K}\right)$ \\
Radiation of platen and tool (external & $\varepsilon=0,6$ \\
surfaces): & \\
Natural convection of platen and tool & $200 \mathrm{~W} /$ \\
(external surfaces): & $\left(\mathrm{m}^{2} \mathrm{~K}\right)$ \\
Ambient/initial temperature & $20^{\circ} \mathrm{C}$ \\
Duration of one casting cycle & $40.7 \mathrm{~s}$ \\
Material properties of casted alloy & $\mathrm{AlSi} \mathrm{Cu} 3(\mathrm{Fe})$ \\
Initial temperature of aluminum alloy & $690^{\circ} \mathrm{C}$ \\
\hline
\end{tabular}

to the occurrence of volumes with a thin wall thickness (e.g., the stiffening structures, see Figure 1) and large volumes (e.g., the fixed and moving platen and column bars) in the model. Large volumes were meshed with a hex-dominant method, using quadratic elements. For smaller volumes, a tetrahedral mesh was applied in ANSYS. In total, the mesh for the lightweight die casting die consists of 6.47E6 nodes and 3.96E6 elements, whereas the mesh for the conventional die casting die contains 1.52E6 nodes and 7.69E5 elements.

\section{Simulation Results}

\section{Thermal Properties}

Due to the lower total mass of a lightweight die compared to a conventional die, it is assumed that the energy consumption is also considerably lower. In order to quantify the differences in energy consumption during preheating and the casting process, finite element models for transient thermal analysis were applied. The investigations take both the preheating and the casting process into account. Table 2 provides an overview of the most important thermal boundary conditions. In order to establish the finite element model, it was necessary to adopt some major 
simplifications. For example, the thermal resistance between individual cavity dies highly correlates to the surface condition and individual assembly methods. Since no precise information can be given at this point, the value was set to $10,000 \mathrm{~W} /\left(\mathrm{m}^{2} \mathrm{~K}\right)$. In contrast to this, numerous research groups have investigated the heat transfer coefficient during solidification of the casting ${ }^{20-26}$ and during the spraying process. ${ }^{27-29}$ An evaluation of the available literature revealed that both heat transfer processes are strongly influenced by the surface temperature, geometry and process parameters. In some cases, the peak values for the heat transfer vary by almost an order of magnitude. ${ }^{25,26}$ These major differences in the heat transfer coefficient are also noticed in Reference 14. The metal/die interfacial heat transfer coefficient was assumed to be a constant value of $20,000 \mathrm{~W} /\left(\mathrm{m}^{2} \mathrm{~K}\right)$, thus taking into account an order that can be found in numerous publications. ${ }^{21,26}$ The heat transfer coefficient during spraying was set to a uniform value of $15,000 \mathrm{~W} /\left(\mathrm{m}^{2} \mathrm{~K}\right)$ for the cavity area and directly adjacent areas. Surface areas that are not directly in the spray cone of the die spraying system were set to a heat transfer coefficient of $3000 \mathrm{~W} /\left(\mathrm{m}^{2} \mathrm{~K}\right)$. Using a model presented by Hattel and Hansen, ${ }^{30}$ Müller points out in his work that for high values of the heat transfer coefficient (e.g., $25,000-100,000 \mathrm{~W} /\left(\mathrm{m}^{2} \mathrm{~K}\right)$ ), only minor changes in the calculated stresses at the die surface occur. ${ }^{31}$ Although not directly comparable, the calculated transient temperature curves in Figure 4 are both quantitatively and qualitatively comparable with the measured temperature curves in References 20 and 22 indicating that realistic boundary conditions were met in principle.

Figure 3 shows the results of the first calculation step, the preheating of the die. Here, both the conventional and the lightweight die were initially set to room temperature and heated by the internal cooling channels (see Table 2) for $4 \mathrm{~h}$. Figure 3 contains the calculated results for the thermal output of the cooling channels as well as the average cavity temperature of the die. It becomes obvious that timetemperature curves are comparable for both die design approaches. In fact, the conventional die even exhibits a slightly faster heating time ( $965 \mathrm{~s}$ compared to $1558 \mathrm{~s}$ for an average cavity temperature of $200{ }^{\circ} \mathrm{C}$ ). In the case of the lightweight die in particular, this might come as a surprise, as there is less material that needs to be heated. This result can be explained by the fact that the cooling channel surface of the lightweight die is smaller by a factor of about 6.3 compared to the conventional die $(2.52 \mathrm{E}-02-1.60 \mathrm{E}-$ $01 \mathrm{~m}^{2}$ ), thus limiting the advantage of a lower mass. This inevitable difference in the cooling channel surface arises from the low thickness of the cavity die (Figure 1, \#7) as well as from the space required for the load-bearing metal structure elements (Figure 1, \#8) and ejector pins. When considering the thermal output, however, it becomes evident that due to differences in mass and cooling channel surface, the required thermal output for preheating is considerably higher for the conventional die. Here, the initial thermal output is about $41 \mathrm{~kW}$ and decreases to a value of about $4.1 \mathrm{~kW}$ after $4 \mathrm{~h}$. In contrast to this, the values for the lightweight die are lower by a factor of about 4-6. Moreover, if an average cavity temperature of $200{ }^{\circ} \mathrm{C}$ is taken as a criterion to start the casting process, it becomes clear that considerable energy is needed for reaching a casting-ready condition of the die (4.2-17.3 MJ). The calculated results for the thermal output also shed a slightly different light on the time-temperature curves since it must be questioned whether the power rating of the necessary temperature control units will be high enough to meet the demands in terms of the thermal output. This is particularly important in view of the fact that the thermal output does not account for losses (e.g., operation of the pump, energy dissipation in fluid flow), which inevitably leads to a higher power rating of the temperature control units. It should be also noted that the ambient temperature of the cooling channels is set to $250{ }^{\circ} \mathrm{C}$ for $t=0 \mathrm{~s}$ in this model. In a real heating process
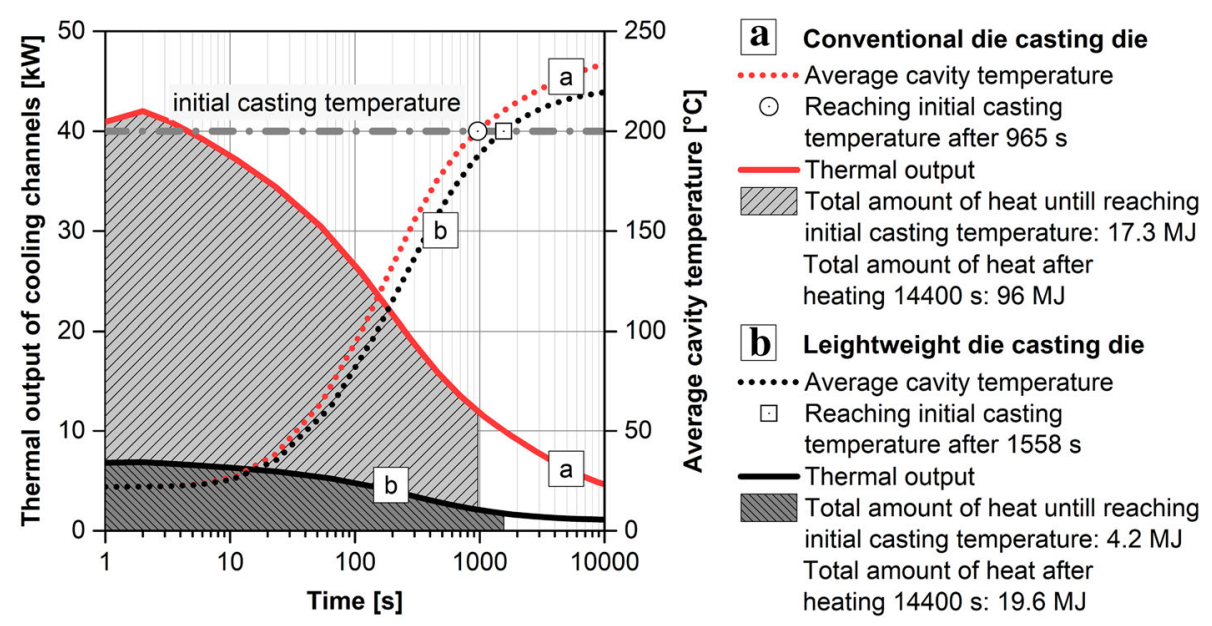

Figure 3. Calculated transient thermal output of cooling channels and average cavity temperature during preheating of a lightweight and conventional die casting die. 
with a temperature control unit and a heat transfer fluid, an additional heating of the fluid and peripheral equipment must be taken into account, which necessarily leads to a slower response of the system in reality.

Figure 4 shows the time-dependent values for the thermal output and the average cavity temperature during the casting process. The displayed values were calculated from the 20th casting cycle after it was found that for this number of casting cycles the difference between the individual cycles converges to less than $1 \%$ of relative change for both design approaches. At this point, it was assumed that quasi-steady-state conditions were reached. With regard to the number of cycles, the same observation was made also in Reference 13. Again, it is noticeable that time-temperature curves show a similar pattern for both die design approaches. However, the overall average cavity temperature of the lightweight die is slightly lower compared to the conventional die. The reason for this behavior is mainly seen in the smaller mass of the lightweight die, which stores less heat required for reheating after the spraying process. With regard to the time-dependent thermal output of the cooling channels during the casting process, it becomes obvious that there is a difference by a factor of about five between both design principles. This surprisingly high factor results from the fact that less heat is removed from the lightweight die during the spraying process because there is significantly less surface, subjected to spraying lubricant and thus energy transfer. Due to its small wall thickness, the lightweight design principle also serves as thermal insulation, which effectively suppresses heat conduction from the cavity die to the fixed and moving platen. Moreover, the cooling channels of the conventional die are located further away from the cavity surface and thereby heat the adjacent areas of the conventional die to a higher extent. These areas in turn exchange more energy with the environment.
To conclude this chapter, Figure 5 displays the heat demand for three different casting lot sizes. Note that this consideration only accounts for the thermal output of the cooling channels and thus does not include the energy required to operate the die casting machine and further peripheral equipment needed. In order to simplify the calculation, it was assumed that both dies were preheated for $4 \mathrm{~h}$, followed by a casting process with a variable number of casting cycles. Considering the difference in the total energy demand between both design principles, it becomes obvious that, regardless of the casting lot size, a factor of approx. 5.2 is calculated. This in turn allows a transition toward smaller casting lot sizes or at least a remarkable reduction in energy costs for large lot sizes. Naturally, the calculated results are linked to the geometry and process conditions and therefore cannot be generalized. However, the calculated results give an outlook on the potential of lightweight dies in terms of a reduced energy demand and the opportunity to use temperature control units with low-power requirements.

Finally, it should be noted that several approaches are conceivable in order to overcome the heat transfer limitations, resulting in reduced heating/cooling rate (see

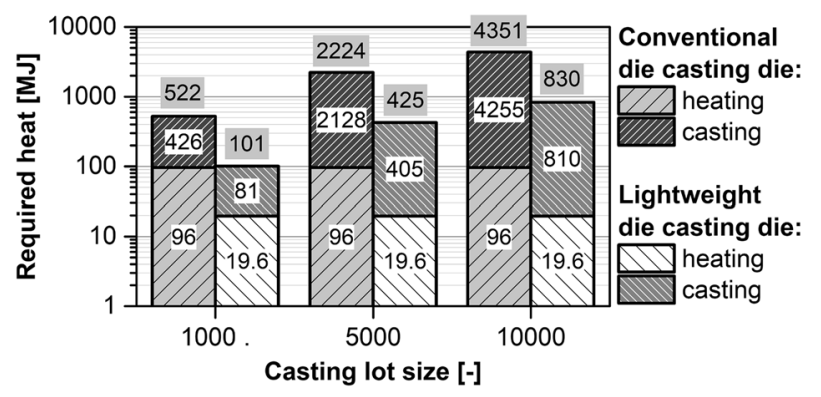

Figure 5. Total energy demand for three different casting lot sizes.
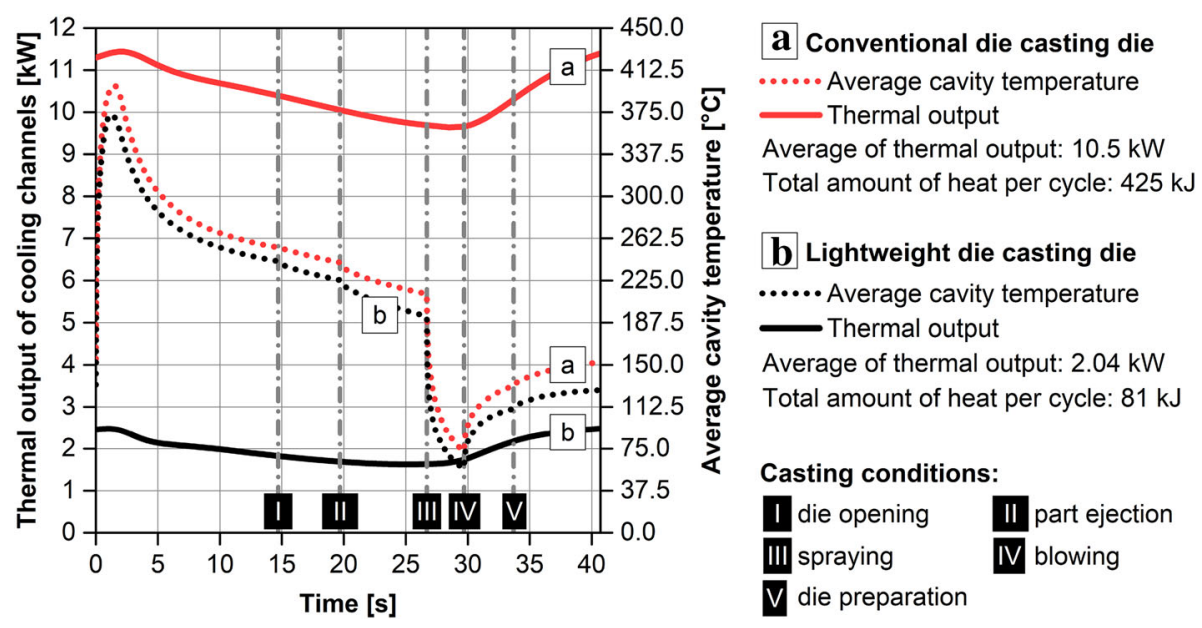

Figure 4. Calculated transient thermal output and average cavity temperature after 20 casting cycles. 
Figure 3). On the one hand, this limitation can be overcome, if die materials with an increased thermal conductivity are used. Recently, die materials possessing a thermal conductivity $50 \%$ higher than the conventional 5\% chromium hot work tool steel, AISI-HI3, were developed as a die material. ${ }^{32,33}$ However, high costs and limitations in the heat treatment have led to the fact that this steel is only used in special cases. Due to the design concept of the lightweight design dies, which have only a relatively small cavity insert, the use of these materials could prove to be effective in this case. On the other hand, advanced methods of die temperature control could also be used here. For example, 3D metal printing processes could be used to integrate cooling channels close to the cavity contour. ${ }^{34}$ Furthermore, the conventional die temperature control system can also be further optimized. In this context, Kimura et al. $^{35}$ have investigated the probability of cracking at the cooling hole. The results enable designers to achieve an advanced design of the cooling channel geometry. Moreover, increased heat transfer fluid rates can significantly contribute to a better heat transfer, as shown in Reference 36 also for die casting dies.

\section{Distortion and Stresses of the Die Casting Die during Operation}

Ensuring a safe operation process throughout the lifetime and the compliance with form and position tolerances are two essential requirements for a high-pressure die casting die. Die casting die distortions are caused by thermal loads from the solidification process as well as by external mechanical stresses produced by the injection pressure and the locking force of the die casting machine. Since the lightweight die exhibits less material and stiffness, it appears to be evident that higher stresses and deformations occur. Hence, a thorough analysis of deformations and stresses during casting operation is of great importance in order to ensure the proper functional characteristics of lightweight die casting dies. As a first step, the differences between the conventional and lightweight die were quantified by finite element methods. This comparison shall include all design and thermal aspects of the dies. Three different basic setups were used for the simulation study (see Table 3). In setup \#I, all possible loads were applied. However, since no heat has been introduced into the system, all investigations were carried out at room temperature. This rather theoretical setup serves to point out the difference in stiffness, irrespective of the influence of additional thermally induced strains. Unlike the first setup, setup \#II exhibits no external mechanical forces. However, the system was subjected to preheating and 20 casting cycles in order to achieve a temperature distribution that is comparable to the temperature distribution of a regular casting process. This setup is intended to determine the thermally induced deformations, regardless of the influence of any additional mechanically induced strains. Setup \#III
Table 3. Basic setups for studying deformation and stresses of high pressure die casting die

\begin{tabular}{lll}
\hline No. & Mechanical loads & Thermal loads \\
\hline I & $\begin{array}{c}\text { All external maximum } \\
\text { loads according to }\end{array}$ & $\begin{array}{c}\text { No heat introduced into } \\
\text { the system }\end{array}$ \\
Figure 2 applied & \\
II $\quad$ No forces applied & System in a casting \\
& & condition (heated up for \\
& 14,400 s by cooling \\
& & channels, 20 casting \\
& cycles) \\
III $\quad$ All external maximum & System in a casting \\
& loads according to & condition (heated up for \\
& Figure 2 applied & $14,400 \mathrm{~s}$ by cooling \\
& channels, 20 casting \\
& cycles) \\
\hline
\end{tabular}

combines the two above-mentioned setups. This setup now takes into account both the thermally induced strains and the external forces. Therefore, this approach should lead to the most realistic conditions with regard to the real die casting process. As with all finite element calculations in this work, the results are based on the specific temperaturedependent material properties of die and machine platen materials (see Table 1).

As previously shown in Figure 1, the investigated die contains the cavity geometry of a plate with a thickness of $4 \mathrm{~mm}$ including the gating system and overflows. This geometry is interesting for two reasons. On the one hand, it ensures to compare the stiffness properties of the die casting die regardless of any stiffness differences, resulting from a complexly shaped cavity geometry. This means that deviations in wall thickness can be attributed directly to the die-and not to stiffness leaps in the cavity area. On the other hand, a flat surface helps to facilitate the understanding of the underlying deformation mechanisms. From a casting point of view, the geometry considered here can also be regarded as a critical application, since the projected surface of this geometry is concentrated in the center of the die, which leads to a challenging case of load application. The wall thickness deviation of the cavity contour for the 4-mm plate was selected as a criterion to evaluate the stiffness of the dies during casting operation, hence giving an indication of achievable form and positional tolerances. Furthermore, the variation in wall thickness is seen as a useful criterion for evaluating the general stability of the casting process and the tendency to burr formation, metal residues adhering to the casting in the area of the parting plane. High deviations in wall thickness necessarily result in a high tendency to burr formation and poor form and positional tolerances. For the evaluation of the wall thickness, the deformation of both die halves was exported from the FE mesh and the 
deviation from the nominal geometry $(4 \mathrm{~mm})$ was calculated and displayed interpolated in ORIGINPRO. Thin-plate spline (TPS), a spline-based technique for data interpolation and smoothing, was used as an interpolation algorithm for this purpose. The following figures given below illustrate the results of the finite element calculations. On the left side, the deformations are shown using the conventional die (Figures 6a, 7a, 8a), on the right-hand side, correspondingly, the deformations when using the lightweight design die (Figures 6b, 7b, 8b). The 4-mm plate has a total dimension of $260 \mathrm{~mm} \times 150 \mathrm{~mm}$, and the distance $x$ equal to zero forms the symmetry line in this case. Similar studies on this subject were carried out by the authors Kim et al. ${ }^{37}$ In the course of their extensive work, the authors also used a 3D scanning technology to measure the deformation of the whole baseplate made of an AZ91D magnesium alloy and drew a deformation pattern. The provided results allow to draw some basic comparisons to experimental measurements. However, the authors mainly focus on the influence of residual stresses in their work.

In Figure 6, it becomes clear that the conventional die exhibits less deformation than the lightweight design die when subjected to a load at room temperature. The reason for this behavior can be found in the lower stiffness of the support structure used in the lightweight die. However, the calculated difference of about $0.05 \mathrm{~mm}$ between both maximums remains relatively small. It is interesting to note that the calculated results for both the magnitude and the qualitative progression agree very well with the experimental values determined in Reference 37 for the baseplate. Figure 7 shows the die deformations at operating temperature (regular casting operation) but without external loads. The deviation between both design concepts is again approx. $0.05 \mathrm{~mm}$ in the center of the plate. The lightweight die exhibits slightly negative values in the

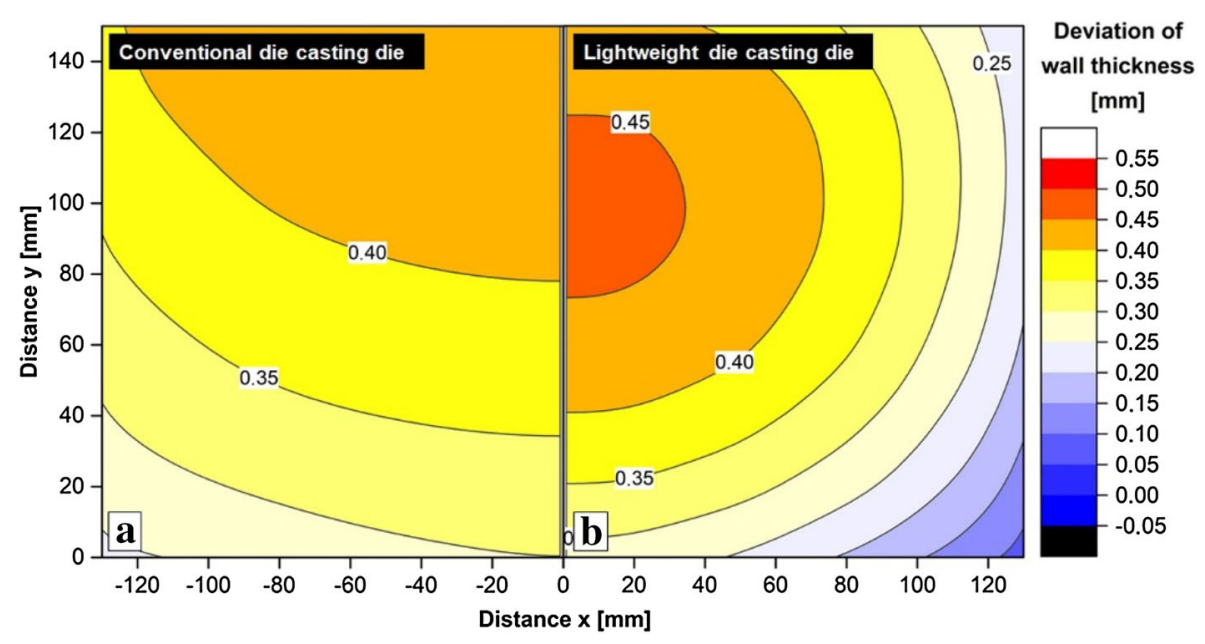

Figure 6. Graphical representation of the wall thickness deviation according to boundary conditions I (see Table 3).

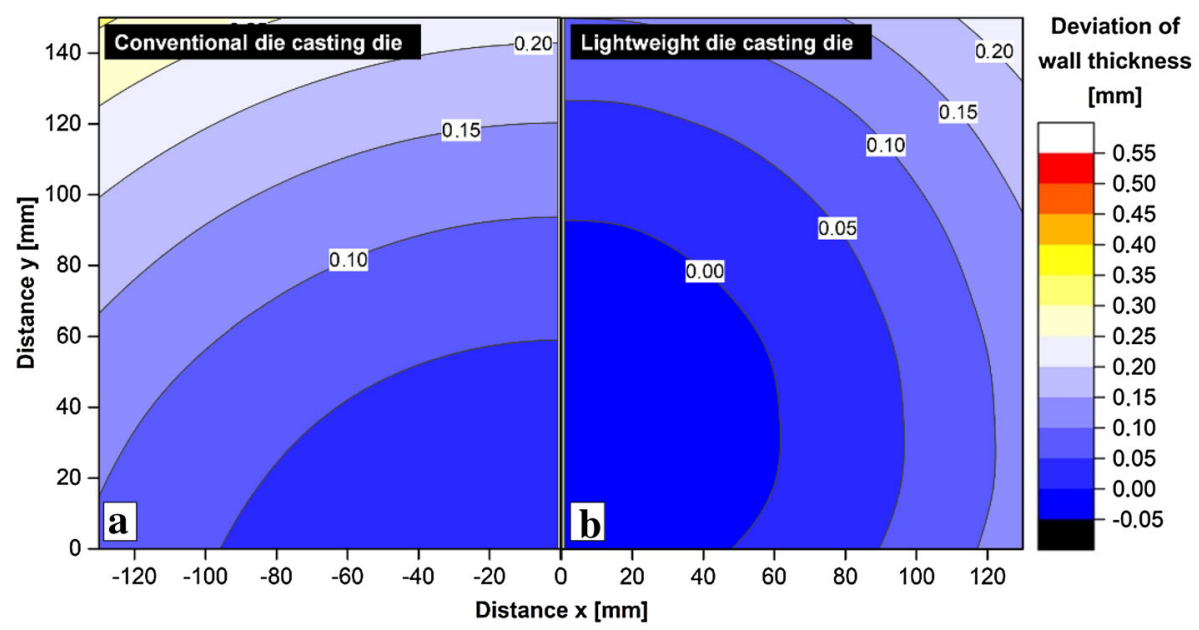

Figure 7. Graphical representation of the wall thickness deviation according to boundary conditions II (see Table 3). 


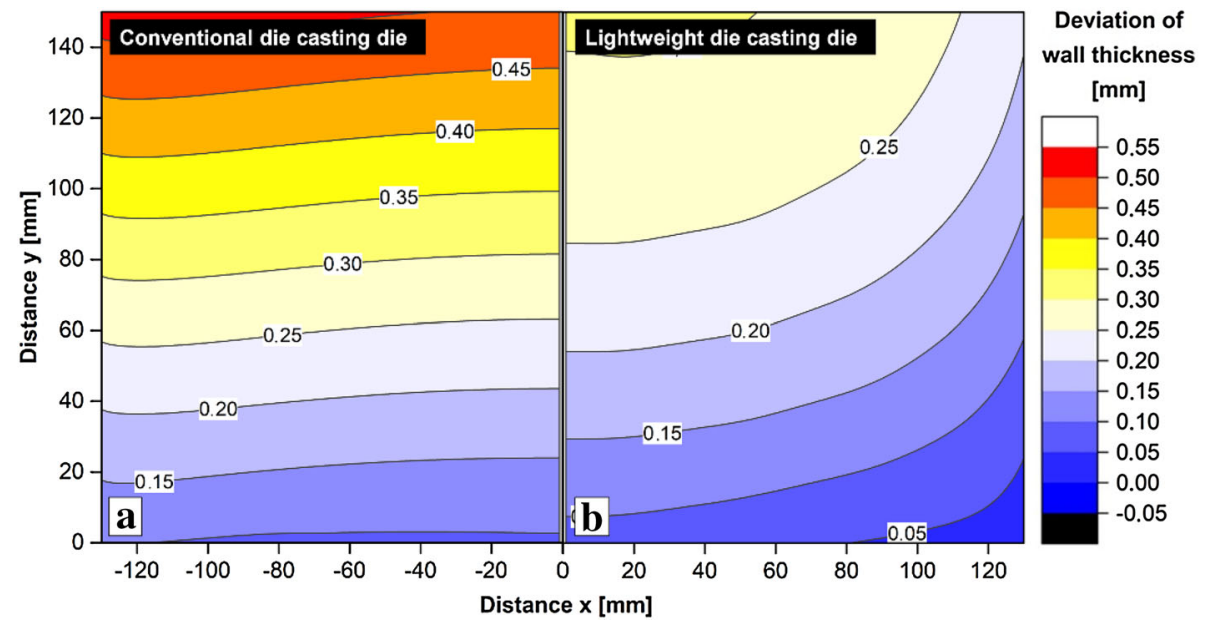

Figure 8. Graphical representation of the wall thickness deviation according to boundary conditions II (see Table 3).
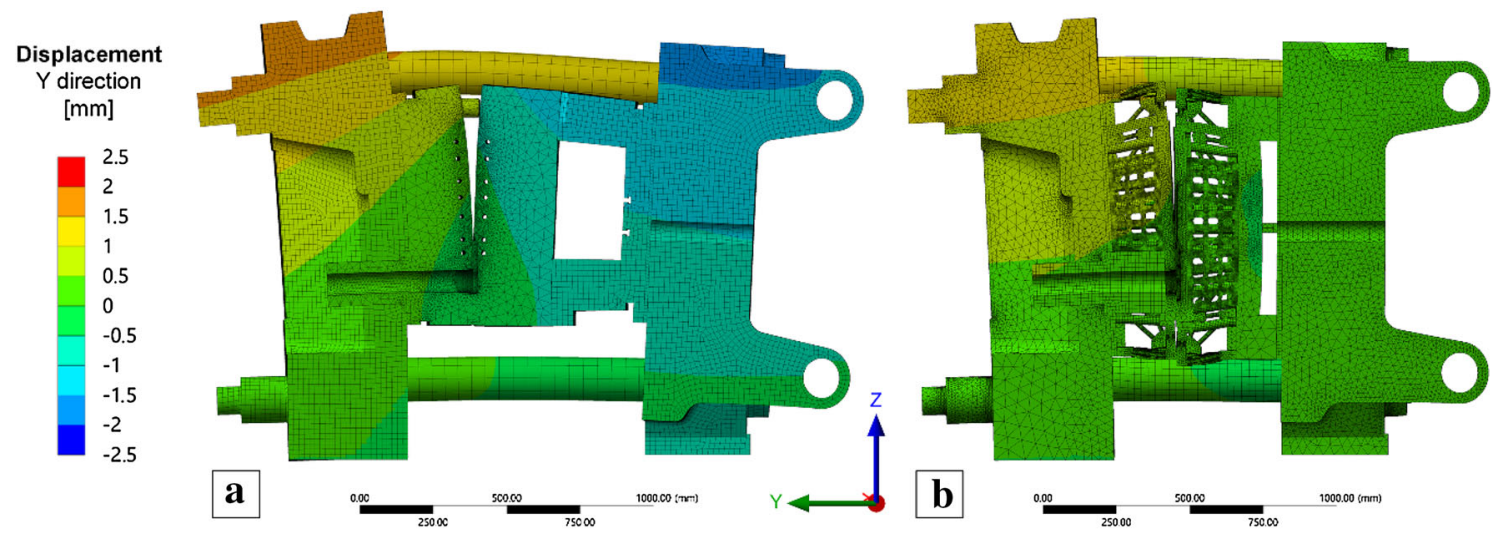

Figure 9. Calculated displacement in y-direction of the functional unit of a high-pressure die casting machine, equipped with a conventional and lightweight die casting die; boundary conditions according to \#III, Table 3; magnification of $40 \times$.

center of the plate, which is attributed to a greater local heat concentration at the cavity. Nevertheless, it can be stated that there are no major deviations in both design concepts, which was to be expected.

Figure 8 shows the most relevant calculated result. Here, both the prevailing temperature distribution and the mechanical loads were taken into consideration. Interestingly, both design concepts now exhibit a different behavior. The lightweight design principle now produces less deviation in wall thickness compared to the conventional design principle. In addition, the deviation of wall thickness is even smaller compared to room temperature (see Figures 6b, 8b). It is assumed that several mechanisms contribute to this behavior. On the one hand, the more localized heating in the area of the cavity die causes the thermally induced expansion to reduce wall thickness if no external load is applied (see Figure 7a, b). This mechanism compensates for the deformations generated in load case III due to the cavity pressure and locking forces. On the other hand, the lightweight design die lacks the guide pins. The result is a different deformation behavior, which especially causes a stronger displacement of the cavity in the z-direction, compared to the conventional die (see Figure 9). Furthermore, as shown in Figure 9, the machine platen equipped with the conventional die casting die tends to be more deformed due to a much higher stiffness of the conventional die, causing the die halves to expand. The deformations of the lightweight design die casting die mainly take place within the die. As it tends to bend more in the middle than the conventional die, the machine platen, therefore, is less deformed. All of these mechanisms result in a lower cavity deformation of the lightweight design die.

In any case, it has to be taken into account that for boundary conditions \#I and \#III (see Table 3), the effective cavity pressure has not yet been coupled with the material 

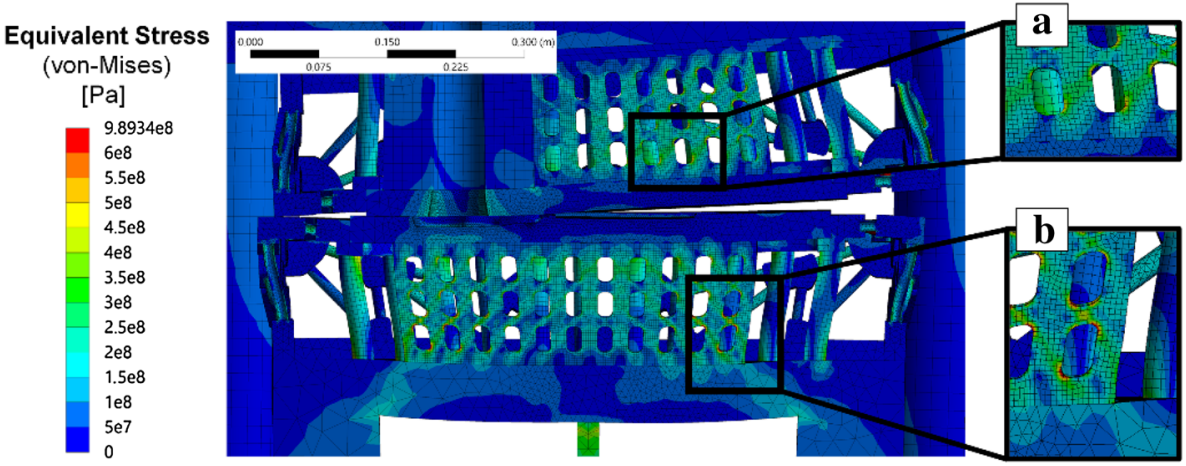

Figure 10. Graphical visualization of the equivalent stresses at the cross section of the lightweight design die.

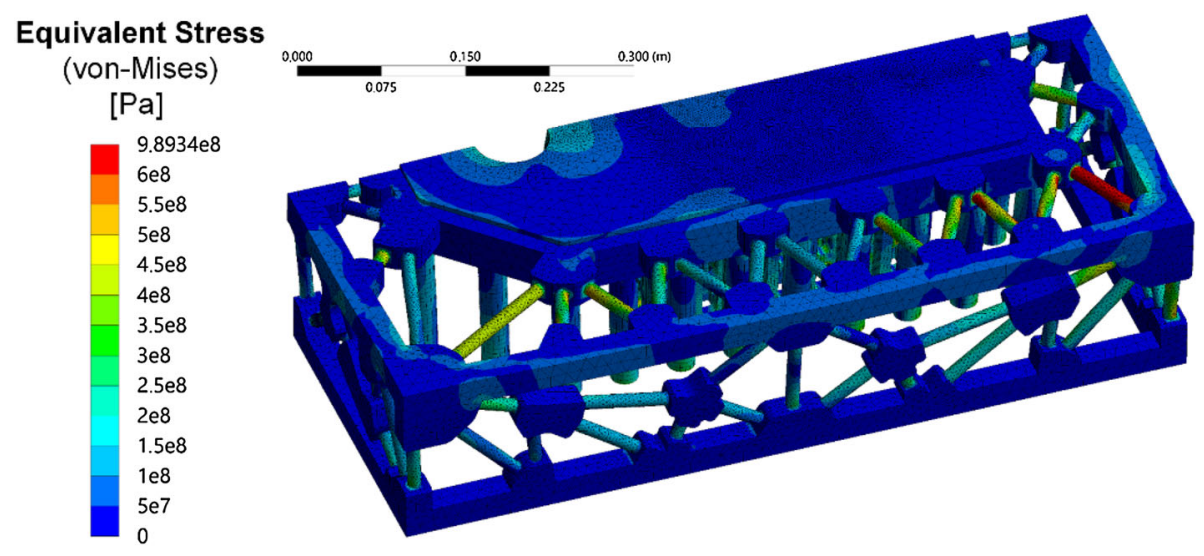

Figure 11. Graphical visualization of the equivalent stresses at the space frame of the lightweight design die.

solidification. The cavity pressure in the actual casting process can only be maintained as long as the ingate is not solidified. A large part of the solidification of the alloy therefore takes place in a cavity which is not subjected to any further cavity pressure. Against this background, it should be noted that the real deviations of the wall thickness are very likely to be smaller than those calculated in simulation. Further investigations must therefore aim at a more precise representation of the actual prevailing loads, taking into account the physical material condition of the light metal alloy. Furthermore, an alternative component geometry should be chosen which is more closely based on real component geometries. The corresponding tool must then also have guide pins, thus creating fundamentally similar boundary conditions to the conventional tool. The evaluation of the deformations should then also be carried out by a direct comparison of the actual and target geometry, e.g., using a best-fit algorithm. In any case, the distance between the two die half surfaces should always be calculated in order to take into account the tendency to burr formation. Nevertheless, the present model has already provided valuable information by demonstrating that it is possible to use the method despite the much lower stiffness of the tool.
In addition to the occurring deformations, an evaluation of die properties also requires a determination of the prevailing stresses within the die casting die. In order to visualize and evaluate multi-axial stress distributions, equivalent von Mises stresses were used. Accordingly, Figures 10 and 11 show the equivalent von Mises stresses occurring for load case III (see Table 3). It becomes clear that very high stresses prevail at the notches of the lightweight load-bearing metal structural element, especially in the area of radii at the peripheral zones (see Figure 10b). Hence, it can be deduced that it is crucial to utilize a material with a high tensile strength at elevated temperatures, tempering resistance and hot toughness. Depending on size, requirements and the underlying manufacturing concept, maraging steels (in the case of advanced manufacturing processes) or classic hot work tool steels, e.g., X38CrMoV5-1 (AISI H11) or X40CrMoV5-1 (AISI H13), as typical materials used for aluminum die casting dies could be used. ${ }^{38-40}$ Furthermore, structural optimization needs to play an important role in order to reduce local stress concentrations and, at the same time, to ensure that there is enough space available to integrate cooling channels and ejectors pins. 
A further consideration must be given to the space frame, composed of optimized 3D trusses. The numerical calculation of stresses shows that high stresses are also calculated locally in these structures (see Figure 11). However, taking into account the results of load cases I-III (load case I-II not displayed here), it becomes clear that these high loads mainly result from the thermally induced deformations during regular casting operations. Therefore, the design of these structures should take into account both thermal and mechanical boundary conditions.

\section{Summary and Outlook}

Within the scope of this article, a die concept was presented which aims at a strong modularization of a highpressure die casting die. The die concept follows the design principle that interchangeable cavity dies containing the part geometry are integrated into a space frame, composed of optimized 3D trusses. The operational load is borne by means of an individually dimensioned lightweight loadbearing metal structural element, which also provides access for ejector pins and cooling channels. Based on the example shown in this publication, a weight saving factor of about $2.3(880 \mathrm{~kg}$ ) was achieved for the die casting die. Furthermore, it was shown that the energy input required to operate the die casting die can be reduced by a factor of about 5.2. The deformations during casting operation are comparable to or below those of the conventional die casting die. In some cases, however, high stresses were also calculated in the lightweight structures, indicating that this point will play an important role in the design and dimensioning of the lightweight design die casting die. Naturally, the quality of the HPDC component also plays a paramount role. The considerations on component quality here only refer to the die deformations. Achievable cooling speeds or the ability of an advanced temperature control in the die were not considered here, as this would go beyond the scope of this article.

From the point of view of the authors, the concept represents a promising opportunity to further enhance the performance of the high-pressure die casting process. It should be clear, however, that this is initially still a concept that serves to evaluate the performance of the design principle. The obtained results have to be transferred step by step into a real die casting die, and experimental measurements of the mechanical and thermal properties as well as investigations on HPDC component quality must be carried out. Results from the experimental measurements must be used to better understand the essential real influencing factors and to subsequently enhance the simulation models. These models in return allow a further virtual optimization of the die properties. This is essential since it has to be noted that dies for real industrial components are usually even more complex, as sliders have to be used for undercuts. The die casting dies also have to meet high demands on form and positional tolerances and must be designed to withstand all possible operational loads that can be obtained during casting operation in order to ensure user safety and process stability. In addition, manufacturing concepts need to be developed which meet the above-mentioned functional requirements and can compete with the manufacturing costs of conventional die casting dies.

\section{Open Access}

This article is distributed under the terms of the Creative Commons Attribution 4.0 International License (http:// creativecommons.org/licenses/by/4.0/), which permits unrestricted use, distribution, and reproduction in any medium, provided you give appropriate credit to the original author(s) and the source, provide a link to the Creative Commons license, and indicate if changes were made.

\section{REFERENCES}

1. H. Lickfett, NE-Metallgießereien in Deutschland: Strukturentwicklung und Strategische Investitionen pro Standort Deutschland (Leichtbau in Guss, Saarbrücken, 2013)

2. R. Schöngrundner, W. Ecker, S. Marsoner et al., Development of a simulation aided design strategy for casting die frames. In: 9th International Tooling Conference, Leoben, Austria, (2012)

3. C. Brecher, D. Özdemir (eds.), Integrative Production Technology: theory and Applications (Springer, Cham, 2017)

4. Y. Queudeville, T. Ivanov, C. Nußbaum et al., Decision and design methodologies for the lay-out of modular dies for high-pressure-die-cast-processes. in Materials Science Forum, (RWTH Aachen, Aachen, 2009), pp. 345-348

5. B. Hummler-Schaufler, C. Schlumpberger, Produktentwicklung auf hohem Niveau. Druckgusspraxis 1, 39-42 (2004)

6. Y. Queudeville, U. Vroomen, A. Bührig-Polaczek, Modularization methodology for high pressure die casting dies. Int. J. Adv. Manuf. Technol. 71(9-12), 1677-1686 (2014). https://doi.org/10.1007/s00170-013-5582-9

7. O. Eitelwein, J. Weber, Unternehmenserfolg durch Modularisierung von Produkten, Prozessen und Supply Chains: WHU Benchmarking-Studie Modularisierung (Books on Demand, Norderstedt, 2011)

8. J.H. Mikkola, O. Gassmann, Managing modularity of product architectures: toward an integrated theory. IEEE Trans. Eng. Manag. 50(2), 204-218 (2003). https://doi.org/10.1109/TEM.2003.810826

9. H. Goehler, J. Meinert, T. Doll et al., Steel hollow sphere structures for energy efficient foaming tools. in 
Cellular Materials-CellMat (International Congress

Center Dresden, Dresden, Germany, 2014)

10. M.R. Barone, D.A. Caulk, A new method for thermal analysis of die casting. Trans. ASME J. Heat Transf. 115, 284-293 (1993)

11. K. Hegde, H. Ahuett-Garza, G. Padiyar, NADCASponsored research: FEM analysis of die casting die deflections: Part I-modeling and simulation. in 18th International Die Casting Congress and Exposition, IN, USA, (1995)

12. H. Ahuett-Garza, K. Hegde, R.A. Miller et al., NADCA-sponsored research: FEM analysis of die casting die deflections: Part 11-results. in 18th International Die Casting Congress and Exposition, IN, USA, (1995)

13. H. Ahuett-Garza, R.A. Miller, The effects of heat released during fill on the deflections of die casting dies. J. Mater. Process. Technol. 142(3), 648-658 (2003). https://doi.org/10.1016/S0924-0136(03)00685-X

14. A. Long, D. Thornhill, C. Armstrong et al., Stress correlation between instrumentation and simulation analysis of the die for high pressure die casting. Int. Metalcast 7(2), 27-41 (2013). https://doi.org/10.1007/BF03355551

15. S.I. Jeong, C.K. Jin, H.Y. Seo et al., Mold structure design and casting simulation of the high-pressure die casting for aluminum automotive clutch housing manufacturing. Int. J. Adv. Manuf. Technol. 228(12), 1599 (2015). https://doi.org/10.1007/s00170-015-7566-4

16. H. Yamagata, Y. Shigenaga, S. Tanikawa et al., Deflection simulation of a die installed in a highpressure die-casting machine. Trans. Jpn. Soc. Mech. Eng. 79(806), 3920-3929 (2013)

17. C.V. Camp, M. Farshchin, Design of space trusses using modified teaching-learning based optimization. Eng. Struct. 62-63, 87-97 (2014). https://doi.org/10.1016/j.engstruct.2014.01.020

18. M. Farshchin, C.V. Camp, M. Maniat, Multi-class teaching-learning-based optimization for truss design with frequency constraints. Eng. Struct. 106, 355-369 (2016). https://doi.org/10.1016/j.engstruct.2015.10.039

19. B. Yalçin, M. Koru, O. Ipek et al., Effect of injection parameters and vacuum on the strength and porosity amount of die-casted A380 alloy. Int. Metalcast 11(2), 195-206 (2017). https://doi.org/10.1007/s40962-016-0046-2

20. G. Dour, M. Dargusch, C. Davidson et al., Development of a non intrusive heat transfer coefficient gauge and its application to high pressure die casting. Metall. Sci. Technol. 22(1), 16-21 (2004)

21. Y. Cao, Z. Guo, S. Xiong, Determination of the metal/ die interfacial heat transfer coefficient of high pressure die cast B390 alloy. IOP Conf. Ser.: Mater. Sci. Eng.
33, 12010 (2012).

https://doi.org/10.1088/1757-899X/33/1/012010

22. Z. Guo, S. Xiong, S. Cho et al., Interfacial heat transfer coefficient between metal and die during high pressure die casting process of aluminum alloy. Front. Mech. Eng. China 2(3), 283-287 (2007). https://doi.org/10.1007/s11465-007-0049-z

23. Z. Guo, S. Xiong, B. Liu et al., Understanding of the influence of process parameters on the heat transfer behavior at the metal/die interface in high pressure die casting process. Sci. China Ser. E-Technol. Sci. 52(1), 172-175 (2009). https://doi.org/10.1007/s11431-008-0295-2

24. Z.-P. Guo, S.-M. Xiong, B.-C. Liu et al., Effect of process parameters, casting thickness, and alloys on the interfacial heat-transfer coefficient in the highpressure die-casting process. Metall. Mater. Trans. A 39(12), 2896-2905 (2008). https://doi.org/10.1007/s11661-008-9640-0

25. A. Hamasaiid, G. Dour, M.S. Dargusch et al., Heattransfer coefficient and in-cavity pressure at the casting-die interface during high-pressure die casting of the magnesium alloy AZ91D. Metall. Mater. Trans. A 39(4), 853-864 (2008). https://doi.org/10.1007/s11661-007-9452-7

26. G. Zhi-peng, X. Shou-mei, L. Bai-cheng et al., Determination of the heat transfer coefficient at metaldie interface of high pressure die casting process of AM50 alloy. Int. J. Heat Mass Trans. 51(25-26), 6032-6038 (2008). https://doi.org/10.1016/ j.ijheatmasstransfer.2008.04.029

27. M. Ciofalo, I. Di Piazza, V. Brucato, Investigation of the cooling of hot walls by liquid water sprays. Int. J. Heat Mass Trans. 42(7), 1157-1175 (1999). https://doi.org/10.1016/S0017-9310(98)00250-6

28. G.W. Liu, Y.S. Morsi, B.R. Clayton, Characterisation of the spray cooling heat transfer involved in a high pressure die casting process. Int. J. Therm. Sci. 39(5), 582-591 (2000). https://doi.org/10.1016/S1290-0729(00)00207-6

29. A.S. Sabau, R.B. Dinwiddie, Characterization of spray lubricants for the high pressure die casting processes. J. Mater. Process. Technol. 195(1-3), 267-274 (2008). https://doi.org/10.1016/j.jmatprotec.2007.05.021

30. J.H. Hattel, P.N. Hansen, A 1-D analytical model for the thermally induced stresses in the mold surface during die casting. Appl. Math. Model. 18(10), 550-559 (1994). https://doi.org/10.1016/0307-904X(94)90140-6

31. S. Müller, Ermittlung der Lebensdauer von Aluminium-Druckgießformen aufgrund thermischer Ermüdung. Zugl.: Braunschweig, Techn. Univ., Diss., 2015. Forschungsberichte des Instituts für Füge- und Schweißtechnik, Shaker, Aachen, 40 (2015)

32. M. Ayabe, T. Nagaoka, K. Shibata et al., Effect of high thermal conductivity die steel in aluminum casting. 
Int. Metalcast 2(2), 47-55 (2008).

https://doi.org/10.1007/BF03355427

33. E. Kaschnitz, P. Hofer, W. Funk, Thermophysikalische Daten eines Warmarbeitsstahls mit hoher Wärmeleitfahigkeit. GIESSEREI 97(9), 46-49 (2010)

34. A. Armillotta, R. Baraggi, S. Fasoli, SLM tooling for die casting with conformal cooling channels. Int. J. Adv. Manuf. Technol. 71(1-4), 573-583 (2014). https://doi.org/10.1007/s00170-013-5523-7

35. T. Kimura, H. Yamagata, S. Tanikawa, FEM stress analysis of the cooling hole of an HPDC die. IOP Conf. Ser.: Mater. Sci. Eng. 84, 12052 (2015). https://doi.org/10.1088/1757-899X/84/1/012052

36. H. Hu, F. Chen, X. Chen et al., Effect of cooling water flow rates on local temperatures and heat transfer of casting dies. J. Mater. Process. Technol. 148(1), 57-67 (2004).

https://doi.org/10.1016/j.jmatprotec.2004.01.040
37. T. Kim, K. Jin, N. Kim et al., Numerical analysis and optimal design to reduce residual stresses and deformations of die casting baseplate after ejection. J. Mech. Sci. Technol. 29(7), 2949-2956 (2015). https://doi.org/10.1007/s12206-015-0625-9

38. D. Klobčar, L. Kosec, B. Kosec et al., Thermo fatigue cracking of die casting dies. Eng. Fail. Anal. 20, 43-53 (2012). https://doi.org/10.1016/j.engfailanal.2011.10.005

39. D. Klobčar, J. Tušek, B. Taljat, Thermal fatigue of materials for die-casting tooling. Mater. Sci. Eng. A 472(1-2), 198-207 (2008).

https://doi.org/10.1016/j.msea.2007.03.025

40. S. Naimi, S.M. Hosseini, Tool steels in die-casting utilization and increased mold life. Adv. Mech. Eng. 7(1), 286071 (2014). https://doi.org/10.1155/2014/286071 